\title{
KYPHOPLASTY AND VERTEBROPLASTY IN THE TREATMENT OF OSTEOPOROTIC VERTEBRAL FRACTURES
}

\author{
CIFOPLASTIA E VERTEBROPLASTIA NO TRATAMENTO DE FRATURAS VERTEBRAIS \\ POR OSTEOPOROSE
}

\section{CIFOPLASTIA Y VERTEBROPLASTIA EN EL TRATAMIENTO DE FRACTURAS VERTEBRALES POR OSTEOPOROSIS}

\author{
García Ortiz Uriel Nahum¹, Fuentes Rivera Miguel Ángel ${ }^{1}$, González Moga Amado', Santos Benitez Hugo Alberto²
}

1. Centro médico ISSEMyM ecatepec, Department of Spine Surgery, Av. del trabajo s/n, esq. av. revolución No. 3030, Col. El carmen, Ecatepec de Morelos, Estado de México, Mexico. 2. Hospital Ruber Quirón Juan Bravo, Department of Brain and Spine Neurosurgery, C/ juan bravo, 49 dup. $4^{\text {a }}$, Madrid, Spain.

\begin{abstract}
Objective: To compare these procedures in the treatment of osteoporotic vertebral compression fractures. Methods: Patients who underwent vertebral augmentation procedures between March 2010 and October 2016 were selected for the study. Kyphosis, anterior vertebral height, Oswestry Disability Index (ODI), Visual Analog Scale (VAS), number of portals, cement volume, and complications were recorded. The results were analyzed by difference of the means. Results: Sixty-eight patients were selected, accounting for 105 procedures. A statistically significant improvement was observed in VAS and ODI with both procedures $(p<0.001)$ without statistically significant difference between them, regardless of the number of portals or cement applied. There was a high correlation between kyphosis correction and ODI improvement $(p=0.012)$. Conclusions: Both vertebroplasty and kyphoplasty are effective procedures for the treatment of vertebral compression fractures. We found no significant difference between both procedures. The high correlation between improvement of kyphosis and ODI suggests that these procedures are better than conservative treatment to improve the quality of life of patients, however more studies are required to reach a final conclusion. Level of Evidence III; Retrospective comparative study.
\end{abstract}

Keywords: Kyphoplasty; Vertebroplasty; Spinal fractures; Osteoporosis; Osteoporotic fractures.

RESUMO

Objetivo: Comparar esses procedimentos no tratamento de fraturas de compressão secundárias à osteoporose. Métodos: Foram selecionados os pacientes que foram submetidos a procedimentos de reforço vertebral no período de março de 2010 a outubro de 2016. Foram registrados angulações, cunhões, índice de incapacidade de Oswestry (ODI), escala visual analógica (VAS), número de portais. volume de cimento e complicações. Os resultados foram analisados por diferenças médias. Resultados: 68 pacientes foram selecionados com 105 procedimentos. Observou-se uma melhoria estatisticamente significativa no EVA e ODI em ambos os procedimentos ( $p<0,001$ ), sem diferenças estatisticamente significativas entre eles, independentemente da quantidade de portais ou cimento aplicado. Uma correlação alta foi encontrada entre a correção da angulação cifótica e a melhora do ODI ( $p=0,012)$. Conclusões: Tanto a vertebroplastia quanto a cifoplastia são procedimentos efetivos para o tratamento de fraturas de compressão. Não encontramos diferenças significativas entre os dois procedimentos. A alta correlação entre a melhora da cifose e o ODI sugere que esses procedimentos são superiores ao tratamento conservador para melhorar a qualidade de vida do paciente, porém são necessários mais estudos para chegar a uma conclusão final. Nível de Evidência III; Estudo retrospectivo comparativo.

Descritores: Cifoplastia; Vertebroplastia; Fraturas da coluna vertebral; Osteoporose; Fraturas por osteoporose.

\section{RESUMEN}

Objetivo: Comparar estos procedimientos en el tratamiento de fracturas por compresión secundarias a osteoporosis. Métodos: Se seleccionaron pacientes a quienes se realizaron procedimientos de refuerzo vertebral en el periodo de Marzo de 2010 a Octubre de 2016. Se registró la angulación, acuñamiento, Oswestry Disability Index (ODI), Escala Visual Análoga (EVA), cantidad de portales, volumen de cemento y complicaciones. Se analizaron los resultados por diferencia de las medias. Resultados: Se seleccionaron 68 pacientes con 105 procedimientos. Se observó una mejoría estadísticamente significativa en el EVA y ODI en ambos procedimientos ( $p<0,001)$, sin diferencias estadísticamente significativas entre estos, independientemente de la cantidad de portales o cemento aplicado. Se encontró una alta correlación entre la corrección de la angulación cifótica y la mejoría del ODI $(p=0,012)$. Conclusiones: Tanto la vertebroplastia como la cifoplastia son procedimientos eficaces para el tratamiento de las fracturas por compresión. No encontramos diferencias significativas entre ambos procedimientos. La alta correlación entre la mejoría de la cifosis y el ODI sugiere que estos procedimientos son superiores al tratamiento consenador para mejorar la calidad de vida del paciente, sin embargo se requieren más estudios para llegar a una conclusión final. Nivel de Evidencia III; Estudio retrospectivo comparativo.

Descriptores: Cifoplastia; Vertebroplastia; Fracturas de la columna vertebral; Osteoporosis; Fracturas osteoporóticas. 


\section{INTRODUCTION}

Osteoporosis is a health issue of global importance. It is estimated that currently there are approximately 10 million people affected in the United States, which will increase to 14 million by $2025 .{ }^{1}$ One of the principal complications is osteoporotic vertebral fractures $(\mathrm{OVF}),{ }^{2,3}$ with a reported incidence of 117 cases per 100,000 inhabitants, representing 1.4 million patients annually. ${ }^{4-7}$ Unlike other types of osteoporotic fractures, OVFs are usually not associated with trauma. ${ }^{8}$ Nonetheless, OVFs are associated with a significant worsening of the morbidity and mortality of patients., ${ }^{6,9}$ Over time, the patients with OVF can suffer from chronic pain, reduced quality of life and functionality, low self-esteem, risk of other fragility fractures, ${ }^{10}$ medullary compression, and changes in pulmonary function. ${ }^{11}$ As regards mortality, an increase of $32 \%$ has been reported, adjusted for the age of the patients with OVF. ${ }^{12}$

Currently, the gold standard in treatment of OVFs remains conservative based on analgesics, rest, and immobilization, 8,13 however, conservative treatment with long periods of inactivity in the elderly patient can produce pneumonia, bed sores, venous thromboembolism, new OVFs, and even death. ${ }^{13,14}$ Coupled with this, in some cases the patients continue to have pain, as well as a reduction in the quality of life despite having undergone appropriate conservative treatment. ${ }^{8,15}$ It is for these patients that vertebral augmentation procedures have appeared as an useful alternative in the treatment of OVFs. 6,8,15,16

Among vertebral augmentation procedures, two have shown to be more effective: vertebroplasty and balloon kyphoplasty (Figure 1).6,8,16 Vertebroplasty was first described for the treatment of aggressive vertebral hemangiomas of the lumbar spine. ${ }^{17}$ Bone cement is injected into the vertebra via a transpedicular approach, which helps to stabilize the vertebral fracture, improving both strength and stability. In balloon kyphoplasty, a cavity is created in the vertebra using an inflatable balloon, thus reducing the pressure from the injection and restoring vertebral height. ${ }^{8}$

Vertebroplasty and kyphoplasty have been shown to be effective in improving both pain and the quality of life of patients with OVF, even when compared to conservative treatment. 6,15,16 However, there is still controversy around whether any of these treatments is more effective or safer in terms of the incidence of complications. . $13,15,16,18$ Another controversy revolves around comparing the effectiveness of and complications resulting from the use of one versus two portals. ${ }^{5,6,16,19}$ For this reason, the objective of this study is to compare the results obtained and the incidence of complications from these two procedures in patients treated in our facility.

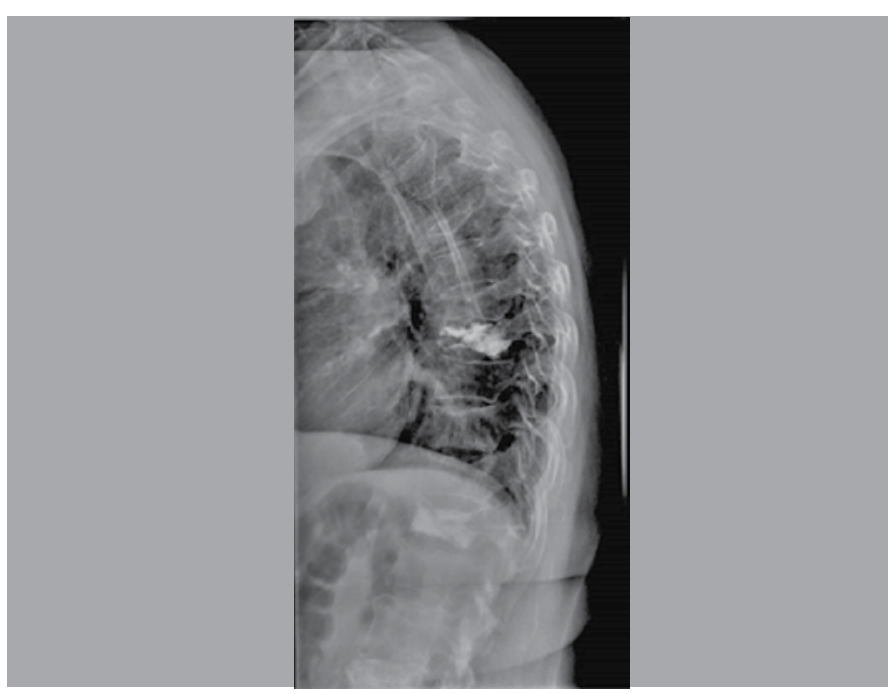

Figure 1. Patient with osteoporotic vertebral fractures at multiple levels treated by vertebroplasty.

\section{METHODS}

\section{Patients}

With the prior authorization of the Institutional Review Board, we conducted a retrospective study of the patients with vertebral compression fractures attended by the team of Dr. Hugo Alberto Santos Benítez at the Ruber Quirón Juan Bravo Hospital in Madrid, Spain, from January 2009 to December 2016. From among those patients, those who had undergone vertebroplasties or kyphoplasties were selected. No distinction was made by the age, sex, number of affected levels, or associated pathologies of the patients. Patients who had undergone vertebral augmentation for other causes (hemangiomas, metastases, multiple myeloma, etc.) or prior spine surgeries were excluded. Likewise, those patients without complete medical records were excluded. Due to the retrospective nature of the study, it was not necessary for the patients to sign the informed consent form.

\section{Parameters evaluated}

General patient data were collected, including age, sex, levels affected, the Oswestry Disability Index (ODI), and pre- and postoperative pain as assessed by the Visual Analog Scale (VAS). The angle of kyphosis, measured using the Cobb method, and the anterior vertebral height were evaluated radiographically before and after surgery. A preoperative STIR sequence magnetic resonance was also performed to determine whether the fracture was recent. Regarding the surgical event, data about the number of portals used per vertebral body, the volume of bone cement injected into the vertebral body, the presence and location of cement leakage, and the presence of other complications were collected. During postoperative follow-up, information was collected about the appearance of new OVFs, for which a new vertebral augmentation procedure would be performed.

\section{Statistical analysis}

Statistical analysis was conducted with SPSS v 22 software (SPSS Inc., Chicago, IL, USA). The categorical variables were presented as percentages and the continuous variables as averages \pm standard deviation (SD). We performed comparison group analysis by means of Chi square $\left(X^{2}\right)$ for the categorical variables and with the Student's t test for the continuous variables, and also searched for a correlation between the quantitative variables with the Pearson correlation. The confidence interval was established at $95 \%$, with a value of $p<0.05$ being statistically significant.

\section{RESULTS}

Of the 99 patients treated during the period, 68 met the study criteria. During follow-up 10 cases of new fractures were encountered, giving a total of 105 vertebral augmentations performed during the period. The average age of the patients was 76.3 years \pm 11.3 , with a predominance of females. The demographic characteristics of the patients, including age, sex, number of affected levels, and the appearance of new fractures are presented in Table 1. The general procedure, including the number of kyphoplasties and vertebroplasties, the number of portals, and the occurrence of cement leakage are found in Table 2. The most often used technique was kyphoplasty with one portal. In terms of the fracture levels, we observed that the vertebrae with the highest incidence of fracture were $L 1, L 2$, and $T 12(T 6=1$, $\mathrm{T} 7=3, \mathrm{~T} 8=5, \mathrm{~T} 9=3, \mathrm{~T} 10=5, \mathrm{~T} 11=5, \mathrm{~T} 12=13, \mathrm{~L} 1=27, \mathrm{~L} 2=20$, $\mathrm{L} 3=8, \mathrm{~L} 4=8, \mathrm{~L} 5=7$ )

We observed improvements for both kyphoplasties and vertebroplasties from the preoperative ODI (51.6\% $16.7 \%$ vs. 56.7\% $15.3 \%)$ to the postoperative ODI $(27.5 \% \pm 19.9 \%$ vs. $24.6 \% \pm 18.8 \%)$ $(p<0.001)$, from the preoperative VAS for pain $(7.7 \pm 2.2$ vs. $8.2 \pm 2.8)$ to the postoperative VAS for pain $(2.9 \pm 2.4$ vs. $2.8 \pm 2.6)(p<0.001)$, from the preoperative kyphotic angle $\left(9.7^{\circ} \pm 11.61^{\circ} \mathrm{vs} .13 .1^{\circ} \pm 13.1^{\circ}\right)$ to the postoperative kyphotic angle $\left(4.71^{\circ} \pm 11.33^{\circ}\right.$ vs. $\left.7.6^{\circ} \pm 12.9^{\circ}\right)$ 
Table 1. Demographic data.

\begin{tabular}{|c|c|}
\hline Characteristic & Number $(\%)$ \\
\hline Total number of patients & 68 \\
\hline \multicolumn{2}{|l|}{ Age } \\
\hline Range & $48-97$ years \\
\hline$<=50$ & $1(1.5 \%)$ \\
\hline $51-60$ & $5(7.4 \%)$ \\
\hline $61-70$ & $14(20.6 \%)$ \\
\hline $71-80$ & $22(32.4 \%)$ \\
\hline $81-90$ & $22(32.4 \%)$ \\
\hline $91+$ & $4(5.9 \%)$ \\
\hline \multicolumn{2}{|l|}{ Sex } \\
\hline Female & $54(79.4 \%)$ \\
\hline Male & $14(20.6 \%)$ \\
\hline Number of fractures treated per patient & 105 \\
\hline 1 & $45(66.2 \%)$ \\
\hline 2 & $22(32.4 \%)$ \\
\hline 3 & $0(0 \%)$ \\
\hline 4 & $1(1.5 \%)$ \\
\hline Appearance of new fractures & $10(14.7 \%)$ \\
\hline
\end{tabular}

Table 2. Characteristics of the performed procedures.

\begin{tabular}{|c|c|}
\hline Characteristics & Value \\
\hline Total number of procedures & 105 \\
\hline Kyphoplasty & $68(64.8 \%)$ \\
\hline Vertebroplasty & $37(35.2 \%)$ \\
\hline \multicolumn{2}{|l|}{ Number of portals } \\
\hline \multicolumn{2}{|l|}{ Kyphoplasty } \\
\hline 1 Portal & $38(36.2 \%)$ \\
\hline 2 Portals & $30(28.6 \%)$ \\
\hline \multicolumn{2}{|l|}{ Vertebroplasty } \\
\hline 1 Portal & $21(20 \%)$ \\
\hline 2 Portals & $16(15.2 \%)$ \\
\hline \multicolumn{2}{|l|}{ Volume of cement applied } \\
\hline Kyphoplasty & $4.8 \mathrm{cc} \pm 2.02$ \\
\hline Vertebroplasty & $4.2 \mathrm{cc} \pm 1.74$ \\
\hline Cement leakage & $12(11.4 \%)$ \\
\hline Disc & $6(5.7 \%)$ \\
\hline Canal & $4(3.8 \%)$ \\
\hline Paravertebral & $1(1 \%)$ \\
\hline Venous & $1(1 \%)$ \\
\hline \multicolumn{2}{|l|}{ Other complications } \\
\hline Hemothorax & $1(1 \%)$ \\
\hline
\end{tabular}

$(p<0.001)$, and from the preoperative anterior vertebral height $(67.9 \% \pm 17.6 \%$ vs. $66.3 \% \pm 20.1 \%)$ to the postoperative anterior vertebral height $(77.4 \% \pm 18.2 \%$ vs. $76.1 \% \pm 17.2 \%)(p<0.001)$. No statistically significant differences were observed between kyphoplasty and vertebroplasty in ODI improvement $(7.97 \% ; p=0.077)$, VAS for pain $(0.61 ; p=0.279)$, kyphotic angle $\left(0.51^{\circ} ; p=0.569\right)$, or vertebral height $(0.34 \% ; p=0.9)$. As regards the development of complications, no statistically significant differences were observed between vertebroplasty and kyphoplasty in the incidence of any type of complication $(p=0.872)$, the appearance of new fractures $(p=0.545)$, or cement leakage $(p=0.654)$.

Comparing the use of 1 versus 2 portals to perform the vertebral augmentation procedure, we did not observe a statistically significant difference in the occurrence of complications $(p=0.869)$, the incidence of new vertebral fractures $(p=0.172)$, or cement leakage $(p=0.234)$. Similarly, we did not observe any statistically significant differences between the use of 1 or 2 portals in ODI improvement $(3.757 \% ; p=0.410)$, VAS for pain $(0.04 ; p=0.939)$, kyphotic angle $\left(0.41^{\circ} ; p=0.637\right)$, or vertebral height $(0.1 \% ; p=0.97)$.

Regarding the volume of cement administered, no statistically significant correlation was observed with the development of complications $(p=0.612)$, the presence of cement leakage $(p=0.375)$, or the appearance of new fractures $(p=0.096)$; nor did we find any statistically significant correlation between the volume of cement administered and the correction of the kyphotic angle $(0.070, p=0.479)$, the anterior vertebral height $(0.083, p=0.401)$, improvement in the ODI $(0.361, p=0.361)$, or improvement in the VAS for pain $(0.011, p=0.909)$. Likewise, no statistically significant correlation was found between correction of the kyphotic angle and improvement in the VAS for pain $(0.051, p=0.604)$, between vertebral height and improvement in the VAS for pain $(0.111$, $p=0.156$ ), or between vertebral height and improvement in the ODI $(0.069, p=0.483)$. However, a strong correlation was found between correction of the kyphotic angle and improvement in the ODI $(0.905, p=0.012)$. Finally, we did not find any correlation between the appearance of new OVFs and correction of the kyphotic angle $(0.17, p=0.911)$ or correction of the anterior vertebral height $(3.59, p=0.435)$.

\section{DISCUSSION}

OVFs are a worldwide health problem, associated with chronic pain, increased morbidity, decreased quality of life, and even an increase in mortality among the patients who suffer from them. ${ }^{10-12}$ Even though conservative treatment continues to be the gold standard in many centers, ${ }^{8,13}$ several studies have reported that vertebral augmentation procedures have shown to be an effective treatment, and even superior to conservative treatment in some studies. . $^{6} 15,16$

In this study, we observed a significant improvement in the patients who were submitted to vertebral augmentation procedures, both in terms of their functionality (ODI) and pain (VAS), which coincides with other similar studies that have been conducted. 6,13,16 It is important to note that there is still controversy around the superiority of either of the vertebral augmentation procedures (kyphoplasty or vertebroplasty). Multiple studies have reached the conclusion that there is no difference between the two procedures in terms of improvement in pain and functionality, which is in agreement with the results obtained in our study. ${ }^{6,13,15,16}$ As regards correction of the angle of kyphosis and of vertebral height, we did not find any statistically significant differences in our study, while other studies favor kyphoplasty over vertebroplasty in order to achieve greater correction of the kyphotic angle. ${ }^{13,15}$ It is possible that this finding is due to the fact that the radiographic measurements of the patients were made by long-term radiographic evaluations and not with a non-standardized technique, as well as because of the lack of homogeneity in the population and the retrospective study design. Thus, a new prospective study in which vertebral height 
and kyphotic angle are measured serially, comparing both procedures, would be useful.

Another important controversy is the comparison between the use of 1 or 2 portals in vertebral augmentation treatments. 5,16,19 Although this controversy is mainly focused on kyphoplasty, in our study we did not find any significant differences between the use of 1 or 2 portals in either vertebroplasty or kyphoplasty, which coincides with multiple previously conducted studies. $5,16,19$ Therefore, from our point of view, a decision will depend on the surgeon's experience, as well as on the situation and the quantity of fractures to be treated.

Another important point in the controversy is the ideal amount of cement that should be administered to achieve a satisfactory outcome, and whether the volume is related to cement leakage or the appearance of new OVFs. ${ }^{6-8,20}$ In our study, we did not observe any relationship between the volume of cement applied and the development of complications with cement leakage or the appearance of new OVFs, or between the volume of cement and both radiographic and clinical improvement. These results are consistent with those reported in the literature, $6,16,20$ so we are not able to recommend the ideal volume of cement for obtaining a satisfactory result or minimizing the occurrence of complications.

A relevant result in this study was the high correlation found between the correction of the kyphotic angle and the patient's functional improvement as evaluated by the ODI, which according to the Pearson correlation coefficient was very high (0.905). Currently, there are few studies that have established a correlation between correction of kyphosis and improvement in the quality of life, and there are contradictory results on this point. 16,21 Unfortunately, as previously mentioned, in our study we did not find any significant differences between vertebroplasty and kyphoplasty for the correction of kyphotic angle. However, several studies agree that the advantage of kyphoplasty over both vertebroplasty and conservative treatment lies in the possibility of a greater correction of the kyphosis. ${ }^{13,15,16}$ There are, however, studies that indicate excessive correction of kyphotic angle as a risk factor for the development of new OVFs adjacent to the treated segment.6,16,20 Despite this, in our study we did not find any relationship between the correction of kyphotic angle and the development of new OVFs, either adjacent or not adjacent. Therefore, adding the high correlation between improved quality of life of the patients and correction of their kyphosis to the fact that no significant difference in the appearance of new OVFs was found, balloon kyphoplasty could be recommended over vertebroplasty. However, it is important to emphasize the need to conduct more studies, mainly of a prospective nature, in which both correction of kyphotic angle and improvement in patient functionality are taken into account.

Our study included patients treated by Dr. Hugo Santos at the Ruber Quirón Juan Bravo Hospital. The fact that the patients were attended by a single surgeon allowed us to reduce the bias in the procedure results. It is important to note that the patients treated in this facility are not covered by the social security system, but rather by private medical insurance companies. This allowed us to give more timely attention to the patients, obtaining adequate results with shorter wait times. In our experience, we have observed that priority attention with shorter wait times to patients with OVF allows a better postoperative prognosis. Timely patient care has improved through the training of human resources in health for adequate diagnosis and timely referral to the proper patient study protocol. Several examples of these human resources in health are services like the Pain Unit, First Contact Physicians, and Rheumatology, among others. Another important factor that has allowed us to improve patient care is the ability to receive laboratory tests and image studies in short periods of time, such as STIR-sequence magnetic resonance being available within 2 to 48 hours. This permits timely programming and rapid care for patients with this condition. Our patient care protocol can be summarized as follows: 1) preferential consultation appointment, generally referred by other patient cares services; 2) magnetic resonance in the STIR sequence to identify the acute-phase levels affected in order to make a surgical decision (Figure 2); 3) preoperative radiographic control study one day prior to surgery to assess the possible increase in the deformity of the patient; 4) timely surgical treatment; 5) follow-up by the bone pathology unit using the study complete protocol, as well as follow-up by our service.

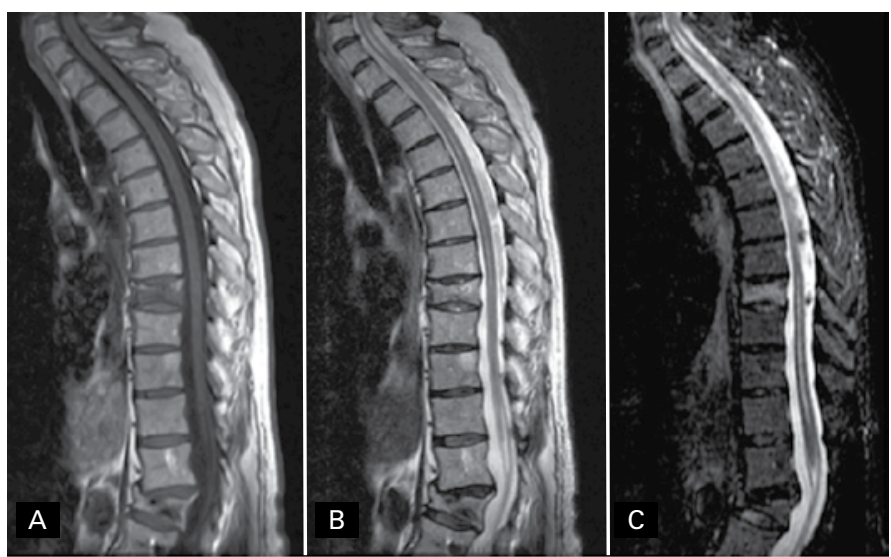

Figure 2. Magnetic resonance of the thoracic spine in phase T1 (A), T2 (B), and STIR $(C)$, showing the difference in intensity, permitting differentiation between acute and chronic fractures.

\section{CONCLUSIONS}

In this study, we concluded that both kyphoplasty and vertebroplasty are useful tools in the treatment of OVFs, achieving significant improvement in the quality of life and pain of the patients. In addition, we found a high correlation between improvement of the kyphotic angle and improvement in the ODI, which represents a better quality of life for patients, with procedures that correct kyphotic angle. It should be noted that, despite the fact that our study did not observe any significant differences between the two procedures, other studies found that balloon kyphoplasty enabled better correction of the kyphotic angle, which is why in our experience it is the most recommendable procedure if improvement in the quality of life of the patient is expected. However, more studies must be conducted to reach a final conclusion. The treatment of these patients must be prioritized to obtain a better patient prognosis. In addition to the initial medical visit, magnetic resonance in the STIR sequence, and radiographic studies should be conducted and surgical treatment should be performed in a timely manner.

All authors declare no potential conflict of interest related to this article.

CONTRIBUTION OF THE AUTHORS: Each author made significant individual contributions to this manuscript. GOUN (0000-0002-6565-8984)* and FRMA (0000-0001-7011-2479)* were the main contributors to the preparation of the manuscript. SBHA (0000-0002-4106-5527)* performed the surgical procedures and patient follow-up. GOUN performed data collection. GOUN, FRMA, and GMA (0000-0003-1745-0334)* evaluated the statistical analysis data. GOUN, FRMA, GMA, and SBHA conducted the bibliographical research, wrote the article, and contributed to the intellectual concept of the study. ${ }^{*}$ ORCID (Open Researcher and Contributor ID). 


\section{REFERENCES}

1. Burge R, Dawson-Hughes B, Solomon DH, Wong JB, King A, Tosteson A. Incidence and Economic Burden of Osteoporosis-Related Fractures in the United States, 2005-2025. J Bone Miner Res. 2007:22(3):465-75.

2. Van der Klift M, De Laet CEDH, McCloskey EV, Hofman A, Pols HA. The incidence of vertebral fractures in men and women: the Rotterdam Study. J Bone Miner Res. 2002;17(6):1051-6

3. Yuan WH, Hsu HC, Lai KL. Vertebroplasty and balloon kyphoplasty versus conservative treatment for osteoporotic vertebral compression fractures: A meta-analysis. Medicine (Baltimore). 2016;95(31):e4491.

4. Johnell $\mathrm{O}$, Kanis JA. An estimate of the worldwide prevalence and disability associated with osteoporotic fractures. Osteoporos Int. 2006;17(12):1726-33.

5. Feng $H$, Huang $P$, Zhang $X$, Zheng $G$, Wang $Y$. Unilateral versus bilateral percutaneous kyphoplasty for osteoporotic vertebral compression fractures: A systematic review and meta-analysis of RCTs. J Orthop Res. 2015;33(11):1713-23.

6. Sebaaly A, Nabhane L, El Khoury Fl, Kreichati G, El Rachkidi R. Vertebral augmentation: State of the art. Asian Spine J. 2016;10(2):370-6.

7. Melton LJ, Kallmes DF. Epidemiology of Vertebral Fractures: Implications for Vertebral Augmentation. Acad Radiol. 2006;13(5):538-45.

8. Savage JW, Schroeder GD, Anderson PA. Vertebroplasty and Kyphoplasty for the Treatment of Osteoporotic Vertebral Compression Fractures. J Am Acad Orthop Surg. 2014;22(10):653-64.

9. Rostom S, Allali F, Bennani L, Abouqal R, Hajiaj-Hassouni N. The prevalence of vertebral fractures and health-related quality of life in postmenopausal women. Rheumatol Int. 2012;32(4):971-80.

10. Pluijm SM, Tromp AM, Smit JH, Deeg DJ, Lips P. Consequences of vertebral deformities in older men and women. J Bone Miner Res. 2000;15(8):1564-72.

11. Schlaich C, Minne HW, Bruckner T, Wagner G, Gebest HJ, Grunze M, et al. Reduced pulmonary function in patients with spinal osteoporotic fractures. Osteoporos Int. 1998;8(3):261-7.

12. Kado DM, Duong T, Stone KL, Ensrud KE, Nevitt MC, Greendale GA, et al. Incident vertebral fractures and mortality in older women: A prospective study. Osteoporos Int. 2003;14(7):589-94.
13. Wang $\mathrm{H}$, Sribastav SS, Ye F, Yang $\mathrm{C}$, Wang J, Liu H, et al. Comparison of Percutaneous Vertebroplasty and Balloon Kyphoplasty for the Treatment of Single Level Vertebral Compression Fractures: A Meta-analysis of the Literature. Pain Physician. 2015;18(3):209-22

14. Klotzbuecher CM, Ross PD, Landsman PB, AbbottTA, Berger M. Patients with prior fractures have an increased risk of future fractures: a summary of the literature and statistical synthesis. J Bone Miner Res. 2000;15(4):721-39.

15. Gu CN, Brinjikji W, Evans AJ, Murad MH, Kallmes DF. Outcomes of vertebroplasty compared with kyphoplasty: a systematic review and meta-analysis. J Neurointerv Surg. 2016;8(6):636-42.

16. Papanastassiou ID, Filis A, Gerochristou MA, Vrionis FD. Controversial issues in kyphoplasty and vertebroplasty in osteoporotic vertebral fractures. Biomed Res Int. 2014;2014:1-12.

17. Galibert $P$, Deramond $H$, Rosat $P$, Le Gars D. Preliminary note on the treatment of vertebral angioma by percutaneous acrylic vertebroplasty. Neurochirurgie. 1987;33(2):166-8.

18. Stevenson M, Gomersall T, Jones ML, Rawdin A, Hernández M, Dias S et al. Percutaneous vertebroplasty and percutaneous balloon kyphoplasty for the treatment of osteoporotic vertebral fractures: A systematic review and cost-effectiveness analysis. Health Technol Assess. 2014;18(17):1-290.

19. Huang Z, Wan S, Ning L, Han S. Is unilateral kyphoplasty as effective and safe as bilateral kyphoplasties for osteoporotic vertebral compression fractures? A metaanalysis. Clin Orthop Relat Res. 2014;472(9):2833-42.

20. Wang YT, Wu XT, Chen $\mathrm{H}$, Wang $\mathrm{C}$, Mao ZB. Adjacent-level symptomatic fracture after percutaneous vertebral augmentation of osteoporotic vertebral compression fracture: a retrospective analysis. J Orthop Sci. 2014;19(6):868-76.

21. Ranstam J, Turkiewicz A, Boonen S, Van Meirhaeghe J, Bastian L, Wardlaw D. Alternative analyses for handling incomplete follow-up in the intention-to-treat analysis: the randomized controlled trial of balloon kyphoplasty versus non-surgical care for vertebral compression fracture (FREE). BMC Med Res Methodol. 2012;12(1):35 